\title{
СРАВНИТЕЛЬНЫЙ АНАЛИЗ АЛЛЕЛЬНОГО СОСТОЯНИЯ ЛОКУСА VvMybA1 У НЕКОТОРЫХ АБОРИГЕННЫХ И ИНТРОДУЦИРОВАННЫХ СОРТОВ ВИНОГРАДА*
}

\author{
А.В. МИЛОВАНОВ 1 , Е.Т. ИЛЬНИЦКАЯ ${ }^{2}$, В.В. РАДЧЕНКО 1 , \\ А.В. ГАРКОВЕНКО'1, А.С. ЗВЯГИН 1 , Л.П. ТРОШИН1', А.Г. КОЩАЕВ1
}

Европейский культурный виноград Vitis vinifira L. - одна из наиболее распространенных сельскохозяйственных культур. Выбор метода культивации винограда и переработки урожая виноградной лозы зависит от того, какой гибрид, клон и подвой используются в производстве, то есть от его ампелографических свойств. За содержание антоцианов в ягодах культурного и дикого винограда ответственно семейство виноградных транскрипционных факторов $V v M y b A$. В настоящей работе у аборигенных российских сортов винограда впервые идентифицированы аллели гена VvMybA1. При этом размер аллелей у окрашенных и неокрашенных сортов был одинаков. Выравнивание последовательностей показало характерные особенности строения аллелей для каждого из изученных генотипов. Нашей целью было выявление, установление особенностей строения и сравнение аллелей гена $V v M y b A 1$ у двух аборигенных и двух интродуцированных в России сортов винограда. В качестве материала были выбраны два окрашенных (Каберне Кортис и Сыпун черный) и два неокрашенных (Шардоне и Сибирьковый) сорта винограда аборигенного и интродуцированного происхождения. Материал верхушечных листьев растений отбирали в Анапской зональной ампелографической коллекции СКФНЦСВВ (АЗОСВиВ). ДНК выделяли согласно модифицированной СТАВ-методике с добавлением меркаптоэтанола. Для проведения ПЦР и выделения искомых аллелей гена $V v M y b A 1$ использовали маркеры, которые позволяют идентифицировать сразу два аллеля - VvMybA1b и $V v M y b A 1 c$. Анализ на соответствие ожидаемому результату проводили посредством поиска последовательности в базе данных GenBank NCBI, используя вебсервисы BLAST, blastx и CD-search. По результатам выравнивания сиквенсов в программе ClustalO была выявлена однонуклеотидная вставка у белоягодных сортов и замены нуклеотидов в разных позициях у сортов с окрашенной и неокрашенной ягодой. При сравнении с базой данных GenBank NCBI было установлено, что нуклеотидные последовательности аллелей гена $V v M y b A 1$ у окрашенных сортов характерны для сортов с ярко выраженной окраской ягод, в то время как у неокрашенных потеря окраски, по-видимому, имела конкретную причину. Так, у сорта Шардоне выявлен аллель, для которого характерна вставка транспозона Gret-1, блокирующего нормальную экспрессию гена $V v M y b A 1$. У сорта Сибирьковый аллель гена $V v M y b A 1$ не функционален из-за блокировки транспозоном Gret-1. Как показано в ряде исследований, этот аллель присутствует и у других неокрашенных сортов. При изучении аминокислотной последовательности, транслируемой с нуклеотидной последовательности анализируемых аллелей, также обнаружены различия между группами окрашенных и неокрашенных сортов. В целом эти различия можно разделить на типичные для окрашенных и неокрашенных сортов, однако при этом у сорта Сыпун черный была выявлена мутация, которая вызвала замену изолейцина на валин, но не повлияла на общую окраску ягод. При поиске в базе данных GenBank NCBI оказалось, что эта мутация не уникальна, так как ее обнаружили у сорта Альфонс Лавалле, а также у межвидовых гибридов.

Ключевые слова: Vitis vinifera L., аборигенные сорта, интродуценты, аллель, ген VvMybA1, секвенирование, антоцианин, мутации, аминокислоты, транспозоны.

Европейский виноград (Vitis vinifera L.) - одна из наиболее распространенных и экономически важных сельскохозяйственных культур. Окраска его ягод входит в число основных характеристик при описании существующих сортов и создании новых форм. Как известно, она зависит от количества и состава антоцианинов, которые окрашенные сорта накапливают в ягодах, в то время как неокрашенные не синтезируют (1).

Выбор метода культивации винограда и переработки урожая виноградной лозы зависит от того, какой гибрид, клон и подвой используются в производстве, то есть от его ампелографических свойств (2). Вегетативное размножение позволило сохранить желаемые признаки, но в значительной

* Работа поддержана РФФИ и Администрацией Краснодарского края, грант № 19-44-233003. 
степени повлияло на частоту спонтанных соматических мутаций, наблюдаемых в полевых условиях $(3,4)$. Из этого следует, что многие признаки были отобраны в результате не только скрещиваний, но и клоновой селекции, например урожайность с куста, форма и компактность грозди, размер и цвет ягод (5-7). Именно как результат гибридизации и мутаций появились сорта, которые формируют промежуточные признаки окраски ягод: розовые, красные, желтые и т.д. На созревание и формирование ягод также влияет окружающая среда (8-10), однако их окраска детерминируется генами. Изначально метаболические пути антоцианового окраса регулируются группой генов $M Y B$ (11-13).

За содержание антоцианов в ягодах культурного и дикого винограда ответственно семейство виноградных транскрипционных факторов $V v M y b A$. Предыдущие исследования показали, что неокрашенный виноград возник благодаря инсерции ретроэлемента в $V v M y b A 1$ (14-16) и мутации однонуклеотидного полиморфизма в $V v M y b A 2(17,18)$. То есть кластер генов, расположенный во 2-й хромосоме, ответственен за большую часть изменения цвета, а фенотип обусловлен совместной работой генов $V v M y b A$ (19). Этот локус состоит из трех генов типа $M Y B$, среди которых $V v M y b A 1$ и $V v M y b A 2$ функционально вовлечены в пигментацию ягод $(13,14)$. На их примере было продемонстрировано, что появление генотипа, характерного для белоягодных сортов, зависит именно от $V v M y b A 1$ и $\operatorname{VvMybA2}(11,13,15)$. Блокирование функционирования гена $V v M y b A 1$ происходит из-за вставки транспозона Gret1 $(16,20)$, в то время как $V v M y b A 2$ может иметь однонуклеотидный полиморфизм (single nucleotide polymorphism, SNP) K980 в кодирующей последовательности, который модифицирует предполагаемую $\alpha$-спираль домена узнавания R2R3 и приводит к потере функциональности аллеля $(15,21)$.

Необходимо отметить, что ранее на территории нашей страны изучались хорошо известные западные сорта-интродуценты, в то время как аборигенные сорта бассейна Черного моря, обладающие огромным селекционным потенциалом для выведения новых гибридов и отбора клонов, остаются неизученными. В частности, не известны структуры их генов, например $V v M y b A 1$, сведения о которых важны для выявления уникального генетического строения аллелей, понимания частных случаев фенотипического разнообразия и изучения эволюции семейства Vitaceae.

В настоящей работе у аборигенных российских сортов винограда впервые идентифицированы аллели гена $V v M y b A 1$. При этом размер аллелей у окрашенных и неокрашенных сортов был одинаков. Выравнивание последовательностей показало характерные особенности строения аллелей для каждого из изученных генотипов.

Нашей целью было выявление, установление особенностей строения и сравнение аллелей гена $V v M y b A 1$ у двух аборигенных и двух интродуцированных в России сортов винограда.

Методика. В качестве материала были выбраны два окрашенных (Каберне Кортис и Сыпун черный) и два неокрашенных (Шардоне и Сибирьковый) сорта винограда аборигенного и интродуцированного происхождения. Материал верхушечных листьев растений отбирали в Анапской зональной ампелографической коллекции СКФНЦСВВ (АЗОСВиВ). ДНК выделяли согласно модифицированной СТАВ-методике с добавлением меркаптоэтанола (22). Для оптимизации последующей ПЦР количество выделенной ДНК измеряли при помощи нанофотометра Implen NP80 («Implen $\mathrm{GmbH»,} \mathrm{Германия),} \mathrm{после} \mathrm{чего} \mathrm{концентрацию} \mathrm{доводили} \mathrm{до} 20$ нг/мкл 
деионизированний водой.

Для проведения классической ПЦР и выявления искомых аллелей гена $V v M y b A 1$ использовали маркеры, описанные A. Azuma c соавт. (23), которые позволяют идентифицировать сразу два аллеля - $V v M y b A 1 b$ и $V v M y b A 1 c$. Смесь для ПЦР объемом 25 мкл включала 20 нг ДНК, 200 мМ dNTP, 0,2 мМ каждого праймера (23), синтезированного ОАО «Евроген», и 1 ед. Таq-ДНК-полимеразы (ОАО «Евроген», Россия). ПЦР проводили в следуюшем режиме: 3 мин при $95{ }^{\circ} \mathrm{C}$ (начальная денатурация); 30 с при $94{ }^{\circ} \mathrm{C}$, 30 с при $65{ }^{\circ} \mathrm{C}, 30$ с при $72{ }^{\circ} \mathrm{C}$ (35 циклов); 10 мин при $72{ }^{\circ} \mathrm{C}$ (ДТ-322, ООО «ДНК-Технология», Россия). Проверку результатов ПЦР на соответствие предполагаемым длинам фрагментов осуществляли в $6 \%$ ПААГ с $1 \times$ ТВЕ буфером, разделение продуктов амплификации проводили в камере для вертикального электрофореза VE-20 («Helicon», Россия) в течение 3 ч (7 B/cм) (маркер молекулярной массы - М12, НПО «СибЭнзим», Россия).

Полученные фрагменты разделяли в $2 \%$ агарозном геле с $0,5 \times$ TAE буфером (5 В/см), после чего их вырезали из гелевой пластины и выделяли при помощи набора Cleanup Standart (ЗАО «Евроген», Россия). Концентрацию ДНК в образце измеряли нанофотометром Implen NP80, объем доводили деионизированной водой до 6 мкл (содержание очищенного амплифицированного фрагмента - 30 нг/мкл).

Секвенирование выполнялось с прямым и обратным ПЦР праймерами (23) для обеспечения большей достоверности (оборудование $3 \mathrm{AO}$ «Евроген», Россия).

Анализ на соответствие ожидаемому результату проводили посредством поиска последовательности в базе данных GenBank NCBI (https://www.ncbi.nlm.nih.gov/genbank), используя веб-сервисы BLAST, blastx и CD-search (24). Выравнивание полученных ДНК и протеиновых последовательностей выполняли при стандартных параметрах в программе ClustalO форматами VIENNA (для выравнивания в fasta формате) и ClustalW (для последующего анализа) (25). Выравненные последовательности анализировали при помощи интерфейса MView (26). Филогенетические отношения между изучаемыми последовательностями аминокислот устанавливали с помощью программы MEGA7 (27) методом Maximum Likelihood (28) с использованием модели Jones-Taylor-Thornton (29) (999 бутстрепов).

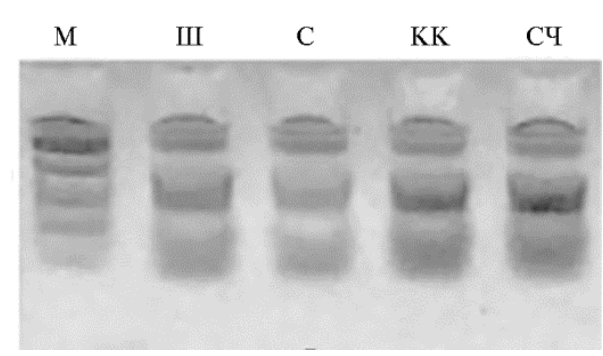

Рис. 1. Разделение продуктов амплификации фрагментов аллелей гена $V v M y b A 1$ у окрашенных (Каберне Кортис - КК, Сыпун черный - СЧ) и неокрашенных (Шардоне Ш, Сибирьковый - С) сортов винограда (Vitis vinifera L.) (M - маркер молекулярных масс М12, НПО «СибЭнзим», Россия; Анапская зональная ампелографическая коллекция СКФНЦСВВ).

Результаты. После разделения продуктов амплификации в агарозном геле (рис. 1) было установлено, что все четыре образца винограда имели аллели гена $V v M y b A 1$, одинаковые по размеру (примерно 850 п.н.). В аналогичных работах на винограде уже была продемонстрирована схожесть ДНК последовательностей, полученных в результате ПЦР, не только по размеру, но и по первичной структуре $(14,16,30)$. Однако, помимо этого, было показано, что одинаковые по размеру области могут быть полиморфными и различаться по структуре, что влияет и на сам признак окраски $(16,21)$. Мы секвенировали амплифицированные участки для установления их нуклеотидных 
CTGTCAGACTTACAAAGGGCTGTCAGTGATACTTGTCTGATGTTGGGCGTGTATAGATGGTCCTTGATGC GGGTAGG

$>$ Kabernet_Cortis_47_1223

AGTCAGCAATTAATTCCTAAATATCTCTTATGACACACACCCTTTGTCCATGAACTCCAGCGCATTTGGAAGCCAGTAATGCACCATAAGAAACGTGTCGAATAAACCAATTAGGGGTCTGGTGTCCGAGTCATGAGATAGAACAGGT GGAGGTTGTTATATATCAATCAATAATTAGAGAAGGAGCCGGTCTCTTGTGTGAGTTGACTCGATGGAGAGCTTA

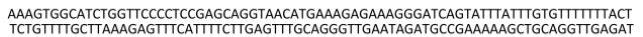

GGCTCAATTATTTGAAGCCGGATATCAAGAGAGGAGAGTTGGATTAGACGAGGTGATCTCATGATTAGGCTTC GGCTCAATTATTGGAAGCCGGATATCAAGAGAGGAGAGTTGCATTAGACGAGGTTGATCTCATGATTAGGCTTC ACAATTGTTGGGGAACAGGCAAGTCTATAATAACTCAAGTACTAGCTTGATAATGATATTATATTAGTICTGAAG
CTGITCAGAACTTACAAAAGAGCTGTCAGTIGATACTTGTCTGATGTGTGCGTGTATAGATGGTCCTTGATTGC GGGTAGG

>Sibirkovii_9_1223

AGTTGATACATAATGGGTAAATATCTCTIATGACACACACCCTTTGTCATGATCTCCAGCGCATTCGGAAGCCAG GTAATGCACCATAAGAAACGTGTCGAATCAACCAATTAGGGGTCTGGTGTCCGAGTCATGAGATAGAACAGGTTC GAGGTIGTTATATATCAATCAATAATTAGAGAAGGAGCCGGTCTCTTGTGTTGAGTTGACTCGATGGAGAGCTTA GAGTTAGAAAGGGTGCATGGACCCAAGAAGAGGATGTTCTCCTGAGGAAATGCATGGAGAAATATGGAGAAG GAAGTGGCATCTGGTICCCCTCCGAGCAGGTAACATGAAAGAGAAAGGGATCAGTATTAGTTTGTGTTTTTTAC TCTGTITGGTTAAAGAGITTCMTITCTIGAGTTGGAGGGTTGAATAGATGCCGAAAAAGCTGCAGGTTGAGA GGCTCAATTATTGAAGCCGGATATCAAGAGAGGAGAGTTTGCATTAGACGAGGTTGATCTCATGATTAGGCTTC ACAATTIGTGGGGAACAGGCAAGTCTATAATAACTCAAGTACTAGCTTGATAATGATATTATATTAGTTCTGAAG CTGITCAGAACTTACAAAAGAGCTGITCAGTTGATACTTIGTCTGATGITGTGCGTGTATAGATGGTCCTTGATTGC GGGTAGG

$>$ Sypun_Chernii_170_1223

agTCAGCAATTAATTCCTAAATATCTCTTATGACACACACCCTTTGTCCATGAACTCCAGCGCATTTGGAAGCC.

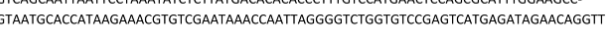
GaGGTTGTTATATATCAATCAATAATTAGAGAAGGAGCCGGTCTCTTGTGTTGAGTTGACTCGATGGAGAGCTTA GAGTTAGAAAGGGTGCATGGATCCAAGAAGAGGATGTTCTCCTGAGGAAATGCGTGAGAAATATGGAGAAG AAAGTGGCATCTGG TICCCCTCCGAGCAGGTAACATGAAAGAGAAAGGGATCAGTATTTATTTGGTTTTTTAC TCTGTTTGCTTAAAGAGTTTCATTTTCTGAGTTTGCAGGGTTGAATAGATGCCGAAAAAGCTGCAGGTTGAGA GGCTCAATTATTGAAGCCGGATATCAAGAGAGGAGAGTTTGCATTAGACGAGGTGATCTCATGATTAGGCTTC ACAATTGTTGGGGACAGGCAAGTCTATAATAACTCAAGTACTAGCTGGATAATGATATTATATTAGTTCTGAAG CGGGTAGG

Рис. 2. Секвенирование одинаковых по размеру (850 п.н.) амплифицированных фрагментов аллелей гена $\boldsymbol{V} \boldsymbol{v} \boldsymbol{M y} \boldsymbol{b} \boldsymbol{A 1}$ у окрашенных (Каберне Кортис и Сыпун черный) и неокрашенных (Шардоне и Сибирьковый) сортов винограда (Vitis vinifera L.) (Анапская зональная ампелографическая коллекция СКФНЦСВВ). Полностью рисунок см. на сайте http://www.agrobiology.ru.

Полученные нуклеотидные последовательности сравнили друг с другом в программе ClustalO (рис. 3):

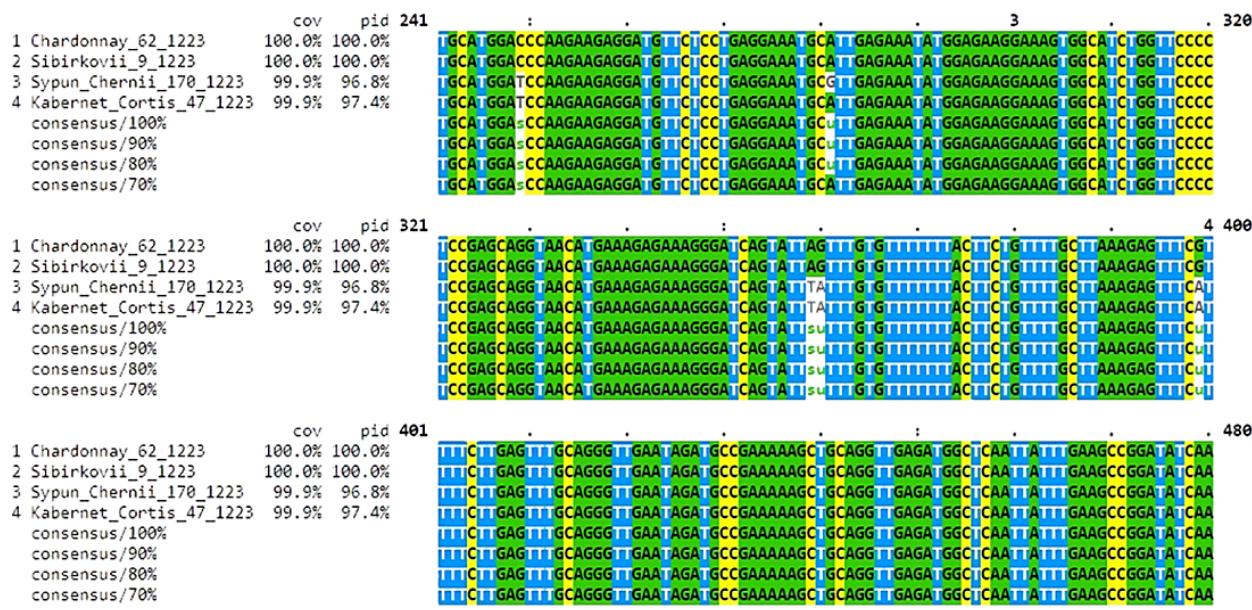

Рис. 3. Анализ участков изученных аллелей гена $V v M y b A 1$ у четырех аборигенных и интродуцированных сортов винограда (Vitis vinifera L.) (окрашенные - Каберне Кортис и Сыпун черный, неокрашенные - Шардоне и Сибирьковый) в программе ClustalO (Анапская зональная ампелографическая коллекция СКФНЦСВВ). Белым цветом выделены нуклеотидные полиморфизмы, выявленные в результате выравнивания анализируемых последовательностей у четыpex генотипов. В 281-й нуклеотидной позиции у сорта Сыпун черный отображена уникальная для выборки нуклеотидная замена, выделенная белым цветом фона. Полностью рисунок см. на сайте http://www.agrobiology.ru.

По результатам выравнивания последовательностей мы обнаружили нуклеотидные замены, которые позволяли различить бело- и красноягодные сорта, например 4-10-й нуклеотиды. Эти различия сиквенсов были выявлены у обеих пар - окрашенных (Сыпун черный и Каберне Кортис) и неокрашенных (Шардоне и Сибирьковый) сортов. То же подтвердил поиск среди последовательностей, депонированных в базы данных GenBank NCBI: при сравнении с ними сходство составило $100 \%$ (за исключением сорта Сыпун черный).

Нуклеотидные последовательности анализируемых аллелей у сортов Шардоне и Сибирьковый оказались идентичными и совпадали с таковой у 
аллеля, характерного для белоягодных сортов, имеющих вставку Gret-1. Этот ретротранспозон, как сообщалось ранее $(16,31)$, блокирует работу аллеля гена $V v M y b A 1$. Следовательно, именно наличие такой вставки в указанном гене подавляет у сорта Сибирьковый синтез антоцианов, окрашивающих ягоды. Несмотря на то, что у сорта Сыпун черный в 281-м нуклеотиде мы выявили уникальную мутацию (см. рис. 3), в целом нуклеотидная последовательность этого аллеля (как и у сорта Каберне Кортис) была характерна для окрашенных сортов (в частности KY406230.1, GU145121.1 и GU145120.1). Интересно, что проявилось сходство именно с аллелем $V v M y b A 1^{S U B}$, который в неэкспрессируемом состоянии обнаруживался у неокрашенных сортов Султанина, Пировано 166А и др. (16), то есть не играл определяющей роли в формировании окраски ягод.

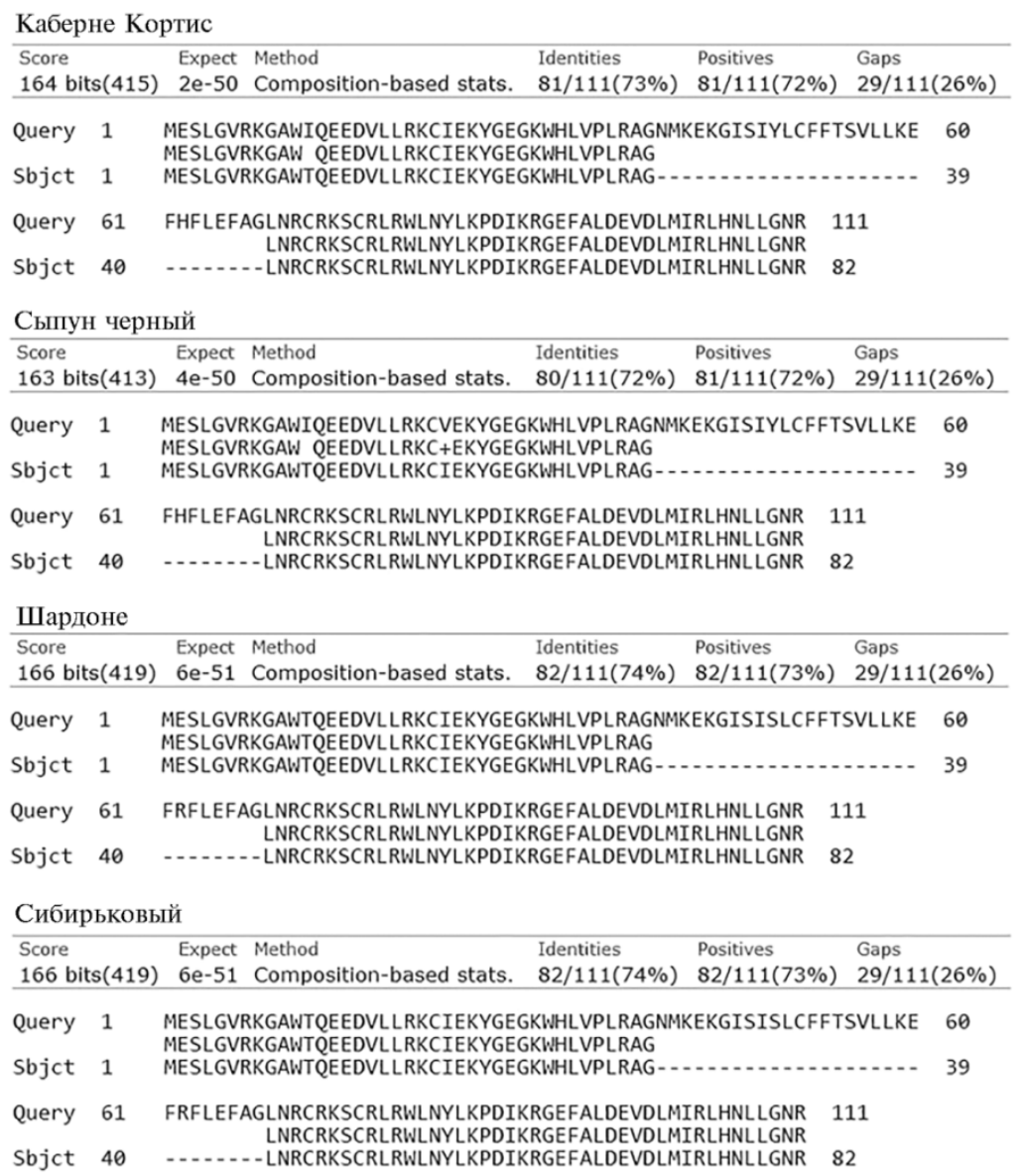

Рис. 4. Результаты поиска аминокислотных последовательностей, транслированных с нуклеотидных последовательностей аллелей гена $V v M y b A 1$ у аборигенных и интродуцированных сортов винограда (Vitis vinifera L.) (окрашенные - Каберне Кортис и Сыпун черный, неокрашенные Шардоне и Сибирьковый), при помощи алгоритмов blastx (Анапская зональная ампелографическая коллекция СКФНЦСВВ). При их сравнении с референсными последовательностями в NCBI Protein (https://www.ncbi.nlm.nih.gov/protein/) была выявлена вставка, которая на рисунках выделена черточками (по всей видимости, интронная последовательность, не удаленная веб-сервисом blastx в процессе трансляции).

После установления принадлежности сиквенсов к искомым аллелям мы провели поиск среди соответствующих им аминокислотных последовательностей, используя веб-сервис blastx. Для всех четырех сиквенсов было установлено предположительное строение аминокислотной цепи (рис. 4). 
Результаты поиска аминокислотных последовательностей через алгоритмы blastx показали 100 \% ее совпадения у всех анализируемых образцов, за исключением крупной вставки в середине сиквенсов (также имеющейся у всех генотипов), которая оказалась переводом интронной области, не исключенной системой по какой-то причине, в последовательность аминокислот. Это утверждение подтверждается также поиском в EnsemblPlants (32) и CDsearch (33).

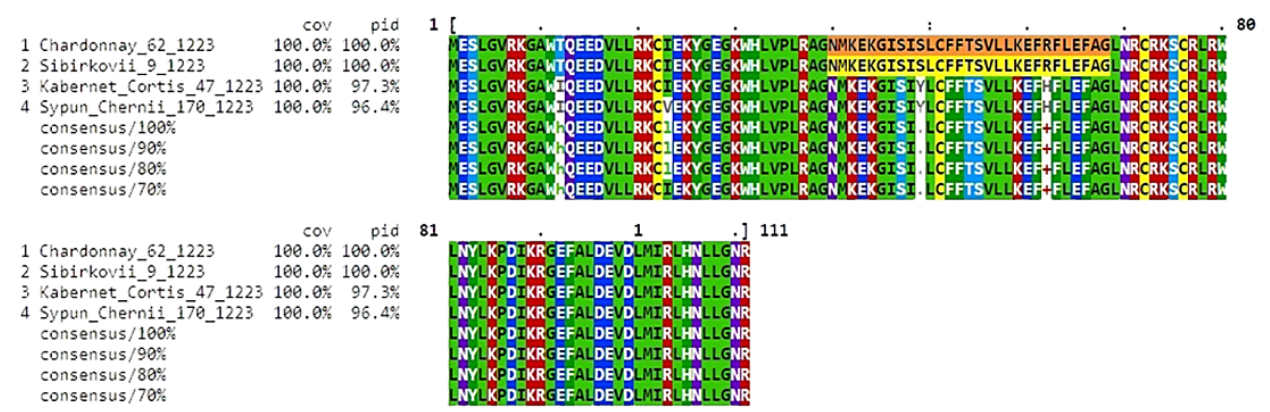

Рис. 5. Выравнивание аминокислотных последовательностей (выделена интронная вставка), транслированных с нуклеотидных последовательностей аллелей гена $V v M y b A 1$ у аборигенных и интродуцированных сортов винограда (Vitis vinifera L.) (окрашенные - Каберне Кортис и Сыпун черный, неокрашенные - Шардоне и Сибирьковый) в программе ClustalO (Анапская зональная ампелографическая коллекция СКФНЦСВВ). У сорта Сыпун черный в 23-й позиции (выделено белым цветом фона) присутствует аминокислотная замена: изолейцин, характерный для трех остальных сортов, замещен на валин. Полностью рисунок см. на сайте http://www.agrobiology.ru.

Показав наличие однонуклеотидных полиморфизмов, мы провели выравнивание аминокислотных последовательностей в ClustalO (рис. 5). Различия между белоягодными и красноягодными сортами были обнаружены по 12-й, 49-й и 62-й аминокислотам. Уникальную замену изолейцина на валин выявили у сорта Сыпун черный в 23-й аминокислоте сиквенса. Помимо этого, два из четырех полиморфизмов располагались в кодирующей части последовательности. Один из них был характерен для бело- и красноягодных генотипов, а 23-я аминокислота у сорта Сыпун черный оказалась уникальной и, согласно CD-search, располагалась в консервативном участке. Примечательно, что в этой позиции не было обнаружено отличий от сорта Альфонс Лавалле (Alphonse Lavallée) (16). Тем не менее оба сорта ярко окрашены. Следовательно, изменение аминокислотной последовательности никак не повлияло на экспрессию этого признака. Поиск аминокислотного сиквенса сорта Каберне Кортис в NCBI Protein подтвердил, что он часто встречается среди межвидовых гибридов, которые имеют схожую последовательность аминокислот, кодируемых $V v M y b A 1(11,13)$, но отличаются от генотипа Сыпун черный заменой валина на изолейцин.

В целом полученные нами результаты соответствовали ожидаемым, поскольку было выявлено, что изученные сорта по нуклеотидным последовательностям аллелей гена $V v M y b A 1$ схожи с известными генотипами. Неожиданным результатом оказалось сходство аминокислотной последовательности, кодируемой аллелем гена $V v M y b A 1$ у сорта Сибирьковый и окрашенных сортов Бенитака, Каберне Совиньон и Родитис (Benitaka, Cabernet Sauvignon, Roditis) $(16,34)$. Этот факт можно объяснить тем, что сорт Бенитака - спонтанный мутант белоягодного сорта Италия (Italia) (31), тогда как сорта Каберне Совиньон и Родитис - это гибриды, несущие оба аллеля $V v M y b A 1 b$ и $V v M y b A 1 c(16,34,35)$. 
Для сравнительного анализа последовательностей генов, детерминирующих окрашенные и неокрашенные ягоды, мы провели их кластеризацию на основе аминокислотных последовательностей (рис. 6). При этом вводили дополнительно генотип Rosa chinensis (XP_024179665.1) из семейства Rosaceae для создания аут-группы.

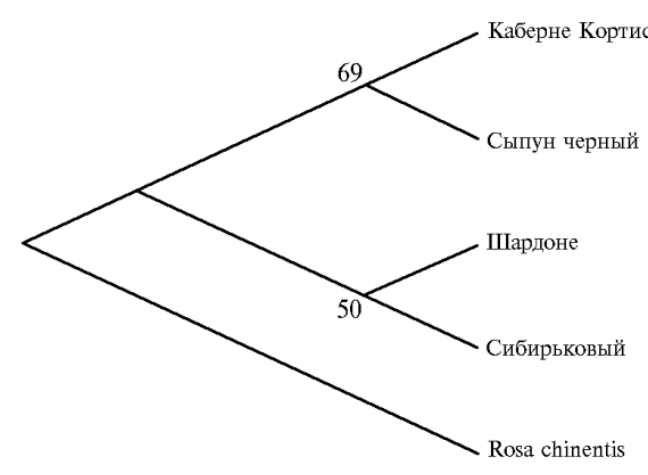

Рис. 6. Кластеризация аборигенных и интродуцированных сортов винограда (Vitis vinifera L.) (окрашенные - Каберне Кортис и Сыпун черный, неокрашенные - Шардоне и Сибирьковый) на основе аминокислотных последовательностей, транслированных с секвенированных последовательностей аллелей гена

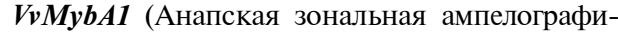
ческая коллекция СКФНЦСВВ). Указаны бутстреп-значения от 50 и выше.

При кластеризации генотипы разделились на три группы: аутгруппу, окрашенные и неокрашенные сорта. Интересно, что программа сформировала древо, на котором белоягодные сорта отделились от основной ветви, расположившись между окрашенными сортами и аут-группой. Эти данные подтверждаются и другими исследованиями. Действительно, некоторые неокрашенные сорта, например Пино блан (Pinot blanc) и Пино гри (Pinot Gris), появились в результате мутации (36), в то время как был также зафиксирован обратный процесс - возвращение окраски у сорта Бенитака, то есть переход от белого цвета ягод к розовому (31).

Таким образом, у интродуцированных и аборигенных российских сортов винограда идентифицированы аллели гена $V v M y b A 1$, размер которых у окрашенных и неокрашенных сортов не различается. В аллелях выявлены уникальные однонуклеотидные замены, присущие конкретным изученным нами генотипам, в том числе уникальная нуклеотидная замена у сорта Сыпун черный, а также вставка у неокрашенных сортов Шардоне и Сибирьковый. Поиск этих последовательностей в базе данных GenBank NCBI с помощью алгоритмов BLAST показал, что три генотипа (сорта Каберне Кортис, Сыпун черный и Шардоне) имели аллели, характерные для белои черноягодных форм. У сорта Сибирьковый аллель гена $V v M y b A 1$ имел сходство с аллелем $V v M y b A l a$, несущим встройку транспозона Gret-1. Очевидно, экспрессия аллеля $V v M y b A 1$ у сорта Сибирьковый блокируется именно этим фактором. Аналогичный результата получен для сорта Шардоне (присутствие транспозона Gret-1, блокирующего функциональную активность аллеля $V v M y b A I)$.

Авторы благодарят компанию ОАО «Евроген» за проведение секвенирования.

\section{ЛИТ Е РАТ УРА}

1. Boss P.K., Davies C., Robinson S.P. Expression of anthocyanin biosynthesis pathway genes in red and white grapes. Plant Molecular Biology, 1996, 32(3): 565-569 (doi: 10.1007/BF00019111).

2. Swanepoel J.J., Southey J.M. The influence of rootstock on the rooting pattern of the grapevine. South African Journal of Enology and Viticulture, 1989, 10(1): 23-28 (doi: 10.21548/10-1-2295).

3. Forneck A. Plant breeding: clonality - a concept for stability and variability during vegetative propagation. In: Progress in botany, vol. 66 /K. Esser, U. Lüttge, W. Beyschlag, J. Murata (eds.). Springer, Berlin, Heidelberg, 2005: 164-183 (doi: 10.1007/3-540-27043-4_8).

4. Pelsy F., Hocquigny S., Moncada X., Barbeau G., Forget D., Hinrichsen P., Merdinoglu D. An 
extensive study of the genetic diversity within seven French wine grape variety collections. Theoretical and Applied Genetics, 2010, 120(6): 1219-1231 (doi: 10.1007/s00122-009-1250-8).

5. Rühl E., Konrad H., Lindner B., Bleser E. Quality criteria and targets for clonal selection in grapevine. Acta Horticulturae, 2004, 652: 29-33 (doi: 10.17660/ActaHortic.2004.652.1).

6. Torres N., Goicoechea N., Morales F., Antolín M.C. Berry quality and antioxidant properties in Vitis vinifera cv. Tempranillo as affected by clonal variability, mycorrhizal inoculation and temperature. Crop and Pasture Science, 2016, 67(9): 961-977 (doi: 10.1071/CP16038).

7. Van Leeuwen C., Roby J.P., Alonso-Villaverde V., Gindro K. Impact of clonal variability in Vitis vinifera Cabernet franc on grape composition, wine quality, leaf blade stilbene content, and downy mildew resistance. Journal of Agricultural and Food Chemistry, 2013, 61(1): 19-24 (doi: 10.1021/jf304687c).

8. Anesi A., Stocchero M., Dal Santo S., Commisso M., Zenoni S., Ceoldo S., Tornielli G.B., Siebert T.E., Herderich M., Pezzotti M., Guzzo F. Towards a scientific interpretation of the terroir concept: plasticity of the grape berry metabolome. BMC Plant Biology, 2015, 15(1): 191 (doi: 10.1186/s12870-015-0584-4).

9. Dal Santo S., Zenoni S., Sandri M., De Lorenzis G., Magris G., De Paoli E., Di Gaspero G., Del Fabbro C., Morgante M., Brancadoro L., Grossi D., Fasoli M., Zuccolotto P., Tornielli G.B., Pezzotti M. Grapevine field experiments reveal the contribution of genotype, the influence of environment and the effect of their interaction $(\mathrm{G} \times \mathrm{E})$ on the berry transcriptome. The Plant Journal, 2018, 93(6): 1143-1159 (doi: 10.1111/tpj.13834).

10. Guidoni S., Ferrandino A., Novello V. Effects of seasonal and agronomical practices on skin anthocyanin profile of Nebbiolo grapes. American Journal of Enology and Viticulture, 2008, 59(1): 22-29.

11. Azuma A., Kobayashi S., Mitani N., Shiraishi M., Yamada M., Ueno T., Kono A., Yakushiji H., Koshita Y. Genomic and genetic analysis of $M y b$-related genes that regulate anthocyanin biosynthesis in grape berry skin. Theoretical and Applied Genetics, 2008, 117(6): 1009-1019 (doi: 10.1007/s00122-008-0840-1).

12. Azuma A., Udo Y., Sato A., Mitani N., Kono A., Ban Y., Yakushiji H., Koshita Y., Kobayashi S. Haplotype composition at the color locus is a major genetic determinant of skin color variation in Vitis $\times$ labruscana grapes. Theoretical and Applied Genetics, 2011, 122(7): 1427-1438 (doi: 10.1007/s00122-011-1542-7).

13. Kobayashi S., Ishimaru M., Hiraoka K., Honda C. Myb-related genes of the Kyoho grape (Vitis labruscana) regulate anthocyanin biosynthesis. Planta, 2002, 215(6): 924-933 (doi: 10.1007/s00425002-0830-5).

14. Kobayashi S., Goto-Yamamoto N., Hirochika H. Retrotransposon-induced mutations in grape skin color. Science, 2004, 304(5673): 982 (doi: 10.1126/science.1095011).

15. Walker A.R., Lee E., Bogs J., McDavid D.A., Thomas M.R., Robinson S.P. White grapes arose through the mutation of two similar and adjacent regulatory genes. The Plant Journal, 2007, 49(5): 772-785 (doi: 10.1111/j.1365-313X.2006.02997.x).

16. Lijavetzky D., Ruiz-García L., Cabezas J.A., De Andrés M.T., Bravo G., Ibáñez A., Carreño J., Cabello F., Ibáñez J., Martínez-Zapater J.M. Molecular genetics of berry colour variation in table grape. Molecular Genetics and Genomics, 2006, 276(5): 427-435 (doi: 10.1007/s00438-0060149-1).

17. Giannetto S., Velasco R., Troggio M., Malacarne G., Storchi P., Cancellier S., De Nardi B., Crespan M. A PCR-based diagnostic tool for distinguishing grape skin color mutants. Plant Science, 2008, 175(3): 402-409 (doi: 10.1016/j.plantsci.2008.05.010).

18. De Lorenzis G. Investigation of $V v M y b A 1$ and $V v M y b A 2$ berry color genes in 'Aglianico' biotypes. In: Progress in Vitis vinfera diversity evaluation and use, vol. 54 /G. De Lorenzis, D. Carrasco, R. Arroyo Garcia, M. Rossoni, G.S. Di Lorenzo, O. Failla (eds.). Bundesanstalt fur Zuchtungsforschung an Kulturpflanzen, Geilweilerhof, 2015: 43-44.

19. Fournier-Level A., Le Cunff L., Gomez C., Doligez A., Ageorges A., Roux C., Bertrand Y., Souquet J., Cheynier V., This P. Quantitative genetic bases of anthocyanin variation in grape (Vitis vinifera L. ssp. sativa) berry: a quantitative trait locus to quantitative trait nucleotide integrated study. Genetics, 2009, 183(3): 1127-1139 (doi: 10.1534/genetics.109.103929).

20. This P., Lacombe T., Cadle-Davidson M., Owens C.L. Wine grape (Vitis vinifera L.) color associates with allelic variation in the domestication gene VvmybA1. Theoretical and Applied Genetics, 2007, 114(4): 723-730 (doi: 10.1007/s00122-006-0472-2).

21. Fournier-Level A., Lacombe T., Le Cunff L., Boursiquot J.M., This P. Evolution of the $V v M y b A$ gene family, the major determinant of berry colour in cultivated grapevine (Vitis vinifera L.). Heredity, 2010, 104(4): 351-362 (doi: 10.1038/hdy.2009.148).

22. Porebski S., Bailey L.G., Baum B.R. Modification of a CTAB DNA extraction protocol for plants containing high polysaccharide and polyphenol components. Plant Molecular Biology Reporter, 1997, 15(1): 8-15 (doi: 10.1007/BF02772108).

23. Azuma A., Kobayashi S., Yakushui H., Yamada M., Mitani N., Sato A. VvmybAl genotype 
determines grape skin color. Vitis, 2007, 46(3): 154-155.

24. McGinnis S., Madden T.L. BLAST: at the core of a powerful and diverse set of sequence analysis tools. Nucleic Acids Research, 2004, 32(suppl_2): 20-25 (doi: 10.1093/nar/gkh435).

25. Sievers F., Higgins D.G. Clustal Omega, accurate alignment of very large numbers of sequences. In: Multiple sequence alignment methods, vol. 1079 /D. Russel (ed.). Humana Press, Totowa, NJ, 2014: 105-116 (doi: 10.1007/978-1-62703-646-7_6).

26. Brown N.P., Leroy C., Sander C. MView: a web-compatible database search or multiple alignment viewer. Bioinformatics, 1998, 14(4): 380-381 (doi: 10.1093/bioinformatics/14.4.380).

27. Kumar S., Stecher G., Tamura K. MEGA7: molecular evolutionary genetics analysis version 7.0 for bigger datasets. Molecular Biology and Evolution, 2016, 33(7): 1870-1874 (doi: $10.1093 / \mathrm{molbev} / \mathrm{msw} 054)$.

28. Murshudov G.N., Vagin A.A., Dodson E.J. Refinement of macromolecular structures by the maximum-likelihood method. Acta Crystallographica, 1997, 53(3): 240-255 (doi: $10.1107 / \mathrm{S} 0907444996012255)$.

29. Jones D.T., Taylor W.R., Thornton J.M. A model recognition approach to the prediction of allhelical membrane protein structure and topology. Biochemistry, 1994, 33(10): 3038-3049 (doi: 10.1021/bi00176a037).

30. Ferreira V., Pinto-Carnide O., Arroyo-García R., Castro I. Berry color variation in grapevine as a source of diversity. Plant Physiology and Biochemistry, 2018, 132: 696-707 (doi: 10.1016/j.plaphy.2018.08.021).

31. Azuma A., Kobayashi S., Goto-Yamamoto N., Shiraishi M., Mitani N., Yakushiji H., Koshita Y. Color recovery in berries of grape (Vitis vinifera L.) 'Benitaka', a bud sport of 'Italia', is caused by a novel allele at the VvmybA1 locus. Plant Science, 2009, 176(4): 470-478 (doi: 10.1016/j.plantsci.2008.12.015).

32. Bolser D.M., Staines D.M., Perry E., Kersey P.J. Ensembl plants: integrating tools for visualizing, mining, and analyzing plant genomic data. In: Plant genomics databases. Methods in Molecular Biology, V. 1533 /A. van Dijk (ed.). Humana Press, New York, NY, 2017: 1-31 (doi: 10.1007/978-14939-6658-5_1).

33. Marchler-Bauer A., Bryant S.H. CD-Search: protein domain annotations on the fly. Nucleic Acids Research, 2004, 32(2): 327-331 (doi: 10.1093/nar/gkh454).

34. Walker A.R., Lee E., Robinson S.P. Two new grape cultivars, bud sports of Cabernet Sauvignon bearing pale-coloured berries, are the result of deletion of two regulatory genes of the berry colour locus. Plant Molecular Biology, 2006, 62(4): 623-635 (doi: 10.1007/s11103-006-9043-9).

35. Bowers J.E., Meredith C.P. The parentage of a classic wine grape, Cabernet Sauvignon. Nature Genetics, 1997, 16(1): 84-87 (doi: 10.1038/ng0597-84).

36. Vezzulli S., Leonardelli L., Malossini U., Stefanini M., Velasco R., Moser C. Pinot blanc and Pinot gris arose as independent somatic mutations of Pinot noir. Journal of Experimental Botany, 2012, 63(18): 6359-6369 (doi: 10.1093/jxb/ers290).

${ }_{1}^{1}$ ФГБОУ ВО Кубанский государственный аграрный университет им. И.Т. Трубилина, 350044 Россия, г. Краснодар, ул. Калинина, 13, e-mail: milovanov1991@mail.ru $\bowtie$, vitalyradchenko@yandex.ru, chief@gene-expert.ru, ziag@mail.ru, lptroshin@mail.ru,kagbio@mail.ru;

2 ФГБНУ Северо-Кавказский федеральный научный центр садоводства, виноградарства, виноделия, 350901 Россия, г. Краснодар, ул. 40 лет Победы, 39, e-mail: ilnitskaya79@mail.ru
Поступила в редакцию 10 октября 2019 года

Sel'skokhozyaistvennaya biologiya [Agricultural Biology], 2020, V. 55, № 3, pp. 523-532

\title{
COMPARATIVE ANALYSIS OF THE $V v M y b A 1$ LOCUS ALLEAL STATE IN SOME INDIGENOUS AND INTRODUCENT GRAPEVINE VARIETIES
}

\author{
A.V. Milovanov', E.T. Ilnitskaya ${ }^{2}$, V.V. Radchenko', A.V. Garkovenko', A.S. Zvyagin', \\ L.P. Troshin', A.G. Koshchaev1
}

${ }^{1}$ Trubilin Kuban State Agrarian University, 13, ul. Kalinina, Krasnodar, 350044 Russia, e-mail milovanov1991@mail.ru ( $₫$ corresponding author), vitalyradchenko@yandex.ru, chief@gene-expert.ru, ziag@mail.ru, lptroshin@mail.ru, kagbio@mail.ru;

${ }^{2}$ North Caucasian Federal Scientific Center of Horticulture, Viticulture, Wine-making, 39, ul. im. 40-letiya Pobedy, Krasnodar, 350901 Russia, e-mail ilnitskaya79@mail.ru

ORCID:

Milovanov A.V. orcid.org/0000-0002-6312-1147 Zvyagin A.S. orcid.org/0000-0002-2684-5875 
Ilnitskaya E.T. orcid.org/0000-0002-2446-0971

Radchenko V.V. orcid.org/0000-0002-4449-3105

Garkovenko A.V. orcid.org/0000-0001-6809-5999

The authors declare no conflict of interests

Acknowledgements:

The authors thank the JSC Evrogen company for the help in sequencing.

Supported financially by Russian Foundation for Basic Research and the Administration of the Krasnodar Territory, grant No. № 19-44-233003

Received October 10, 2019
Troshin L.P. orcid.org/0000-0001-5177-352X

Koshchaev A.G. orcid.org/0000-0002-3904-2860

\section{Abstract}

European cultivated grape Vitis vinifira L. is one of the most common agricultural crops grown by man since ancient times. Of course, the usual companion of the cultivation of this culture is a traditional hybridization and clonal selection, which allows you to select spontaneous mutants. Nevertheless, the study of such an important agrobiological trait as anthocyanin coloration and, in particular, the genes that determine it, is one of the most important problems both in modern grape genetics and in studies of plant metabolic pathways in general. The study of this problem can not only provide the basis for subsequent fundamental research on the functioning of both individual genes and the genome as a whole, but also create a basis for the selection of varieties for economically valuable traits. The $V v M y b A$ family of grape transcription factors is responsible for anthocyanin accumulation in berries of cultivated and wild grapes. In the present work, alleles of the $V v M y b A 1$ gene were first identified in native Russian grape varieties. Theses alleles in the colored and uncolored grape varieties were found out to be the same in size. Sequence alignment showed the characteristic features of alleles for each of the studied genotypes. The purpose of our study, we set a description of the four alleles of the VvMybAl gene in the Chardonnay, Sibirkovskii, Cabernet Cortis and Sypun cherny varieties. Two introduced and well-known varieties and two indigenous varieties also cultivated in the Krasnodar Territory were investigated. The leaves for DNA extraction was collected at the Anapa zonal experimental station. DNA was isolated by CTAB method with mercaptoethanol. PCR was performed using primers and amplification parameters published in the literature. For PCR amplification and isolation of $V v M y b A l$ gene alleles we used markers which allow simultaneous identification of two alleles, $V v M y b A 1 b$ and $V v M y b A 1 c$. We sequenced and compared with each other and with the GenBank NCBI database the sequences of the $V v M y b A 1$ gene alleles of these varieties. Alignment of sequences in the ClustalO program revealed structural features of the allele nucleotide sequences. In particular, a single nucleotide insert was found in white-berry varieties and nucleotide substitutions in different places in varieties with colored and uncolored berries. Further, comparing with the GenBank NCBI database found that the alleles of colored varieties have a structure characteristic for varieties with a pronounced color of berries, while uncolored varieties apparently have a specific reason for the loss of color. Thus, it was found that the Chardonnay variety has an allele with the insertion of Gret-1 transposon which blocks the normal expression of $V v M y b A 1$ gene. It was also revealed that the Sibirkovky variety also has the allele of $V v M y b A 1$ gene which is not functional due to the blocking by Gret-1 transposon. As shown in previous studies by other authors, this allele is also present in other uncolored varieties, and, therefore, this is the reason for blocking gene expression. A study of the amino acid sequence also revealed differences between the groups of colored and uncolored varieties. These differences can be obviously divided into those characteristic of colored and uncolored varieties. However, a mutation was detected in Sypun cherny variety, which affected the replacement of the amino acid isoleucine with valine, but did not affect the overall color of the berries. When searching for the amino acid sequence in the GenBank NCBI database, it was revealed that this mutation is not unique in nature, as it was found in the Alphonse Lavallée variety, as well as in interspecific hybrids.

Keywords: Vitis vinifera L., indigenous varieties, introduced varieties, allele, gene, VvMybA1, sequencing, anthocyanin, mutations, amino acids, transposons. 